\title{
Side Effects of Standard Adjuvant and Neoadjuvant Chemotherapy Regimens According to Age Groups in Primary Breast Cancer
}

\author{
Mattea Reinisch ${ }^{\mathrm{a}} \quad$ Gunter von Minckwitz $^{\mathrm{a}} \quad$ Nadia Harbeck $^{\mathrm{b}} \quad$ Wolfgang Janni $^{\mathrm{c}} \quad$ Sherko Kümmel $^{\mathrm{d}}$ \\ Manfred Kaufmann ${ }^{\mathrm{e}}$ Dirk Elling ${ }^{f} \quad$ Valentina Nekljudova $^{\mathrm{a}} \quad$ Sibylle Loibl ${ }^{\mathrm{a}, \mathrm{g}}$ \\ ${ }^{a}$ German Breast Group, Neu-Isenburg, ${ }^{b}$ Frauenklinik, Universitätsklinikum München, ${ }^{c}$ Frauenklinik, Universitätsklinikum Ulm, \\ ${ }^{\mathrm{d}}$ Frauenklinik, Klinikum Essen Mitte, Essen, ${ }^{\mathrm{e}}$ Frauenklinik, Universitätsklinikum Frankfurt/M., ${ }^{\dagger}$ Arbeitsgemeinschaft Gynäkologische \\ Onkologie, Frauenklinik Sana Klinikum Berlin-Lichtenberg, ${ }^{9}$ Brustzentrum, Klinikum Offenbach, Germany
}

\section{Keywords}

Elderly · Chemotherapy - Side effect - Tolerability . Breast cancer

\section{Summary}

Background: Elderly breast cancer patients are underrepresented in clinical trials and this leads to a lack of knowledge regarding the tolerance and side effects of modern chemotherapy regimens, especially in dosedense (dd) or dose-intensified combination. Patients and Methods: In this analysis, data from 4 German, randomized (neo-)adjuvant trials, including anthracycline-based chemotherapy, were evaluated for toxicity, compliance and feasibility. Patients were grouped according to age. Results: Of the 4,775 patients, $73.6 \%$ were $<60$ years, $15.8 \%$ were $60-64$ years and $10.6 \%$ were $>64$ years. The patients' compliance decreased with increasing age, the rate of therapy discontinuations was $10.3 \%$; $16.0 \%$ were $>64$ years old $(p<0.001)$. The rate of dose reductions also increased with increasing age in the docetaxel/ doxorubicin/cyclophosphamide $($ TAC) $(p$ overall $=0.02)$ and 5-fluorouracil/epirubicin-cyclophosphamide $\left(\mathrm{FE}_{120} \mathrm{C}\right)$ ( $p$ overall $<0.001$ ) treatment groups. Neutropenia grade $3+4$ in patients of $>64$ years was $77 \%$ in $\mathrm{FE}_{120} \mathrm{C}$ - compared to $55 \%$ in TAC-treated patients (with primary granulocyte colony-stimulating factors (G-CSFs)). The incidence of febrile neutropenia (FN) was lowest in the regimens without additional taxanes. $\mathrm{FN}$ in patients aged $>64$ years was lower in the $\mathrm{FE}_{120} \mathrm{C}$ - than in TACand dd-doxorubicin/docetaxel-treated groups. Conclusion: The range and intensity of toxicity increased with age. Neutropenia did not increase significantly in the dd groups; the highest rate was seen in $\mathrm{FE}_{120} \mathrm{C}$-treated patients. $\mathrm{FE}_{120} \mathrm{C}$ without $\mathrm{G}-\mathrm{CSF}$ is not an option in patients older than 64 years.

\author{
Schüsselwörter \\ Chemotherapie bei älteren Patientinnen . \\ Nebenwirkungen - Verträglichkeit
}

\section{Zusammenfassung}

Hintergrund: Ältere Patientinnen mit Brustkrebs sind in klinischen Studien unterrepräsentiert, was zu einem Kenntnismangel in Bezug auf die Nebenwirkungen und die Effektivität von Brustkrebstherapien führt. Vor allem bei dosis-dichten (dd) oder dosis-intensivierten Chemotherapieregimen wird diese Patientinnengruppe vernachlässigt. Patienten und Methode: In der vorliegenden Analyse werden Daten aus 4 deutschen, randomisierten, (neo)adjuvanten, anthrazyklinbasierten Studien ausgewertet hinsichtlich der Toxizität, Compliance und Machbarkeit. Die Patientinnen wurden entsprechend ihres Alters in 3 Kategorien unterteilt. Ergebnisse: Von den 4775 eingeschlossenen Patientinnen waren 73,5\% < 60 Jahre, 15,8\% 60-64 Jahre und 10,6\% > 64 Jahre alt. Die Compliance nahm mit zunehmendem Alter ab, die Rate der Therapieunterbrechungen nahm signifikant zu $(p<0,001)$. Die Rate der Dosisreduzierungen stieg mit zunehmendem Alter an bei Patientinnen, die Docetaxel/ Doxorubicin/Cyclophosphamide (TAC) $\left(p_{\text {overall }}=0,02\right)$ und Patientinnen, die 5-Fluorouracil/Epirubicin-Cyclophosphamide $\left(\mathrm{FE}_{120} \mathrm{C}\right)$ erhielten. Neutropenien Grad $3+4$ entstanden bei Patientinnen > 64 Jahren häufiger bei $\mathrm{FE}_{120} \mathrm{C}(77 \%)$ als bei TAC (55\%) trotz G-CSF-Gabe. Die Inzidenz der febrilen Neutropenien war bei Regimen ohne zusätzliches Taxan am geringsten. Zusammenfassung: Das Ausmaß und die Intensität der Nebenwirkungen stiegen mit zunehmendem Alter an. Neutropenien stiegen in den dd-Gruppen nicht signifikant an, die höchste Rate wurde bei $\mathrm{FE}_{120} \mathrm{C}$-Patientinnen beobachtet. $\mathrm{FE}_{120} \mathrm{C}$ ohne G-CSF bei Patientinnen > 64 Jahren scheint keine Therapiemöglichkeit zu sein.

\section{KARGER \\ Fax +497614520714 \\ Information@Karger.com}

www.karger.com (c) 2013 S. Karger GmbH, Freiburg

$1661-3791 / 13 / 0081-0060 \$ 38.00 / 0$

Accessible online at:

www.karger.com/brc
Prof. Dr. med. Sibylle Loib

German Breast Group

Martin-Behaim Strasse 12,63263 Neu-Isenburg, Germany

Sibylle.Loibl@germanbreastgroup.de 


\section{Introduction}

More than $50 \%$ of all breast cancers (BCs) are diagnosed in patients older than 65 years. Because elderly patients are underrepresented in clinical trials, level 1 evidence on treatment for this population is scarce. Treatment recommendations for younger women cannot simply be carried over to elderly patients [1-3], but undertreatment could lead to higher rates of $\mathrm{BC}$ recurrences and mortality $[4,5]$.

Various study groups have published retrospective analyses, showing that older patients derive the same benefit from standard chemotherapy as younger patients [5, 6]. Muss et al. [7] demonstrated that adjuvant chemotherapy (cyclophosphamide, methotrexate, and fluorouracil) is superior to capecitabine monotherapy in patients $>65$ years, suggesting that elderly women need to be treated according to standard treatment recommendations. 4 cycles of 3-weekly epirubicin/ cyclophospamide are no longer considered the standard of care, especially in patients with node-positive BC.

Several meta-analyses [8] have shown that the overall outlook for women diagnosed with early BC has improved in recent decades. Anthracyclines are still considered to be one of the most potent cytotoxic drugs for BC patients. Our study group has already shown that elderly patients are able to cope with a variety of taxane-containing regimens [9]. A major issue in treating elderly patients with chemotherapy is toxicity. Bone marrow reserves and renal function decrease with age, increasing the probability of myelosuppression and the risk of toxicity. The occurrence of myelosuppression, cardiodepression, peripheral neuropathy, and neurotoxicity can complicate treatment $[10,11]$.

The aim of this analysis was to compare data on acute toxicity and tolerability in different age groups with a focus on the elderly population receiving modern anthracycline- and taxane-containing chemotherapy for BC.

\section{Materials and Methods}

Data from 4 German prospectively randomized clinical trials, conducted between 1999 and 2005, were pooled. These trials included primary BC patients receiving anthracycline-containing chemotherapy. The metadatabase was closed in October 2006; the number of patients in the present analysis may, therefore, differ from the respective individual study publications. For every study the number of patients included in the present analysis exceeds $75 \%$ of those evaluable. Toxicity data from the studies were analyzed for anthracycline-containing chemotherapy regimes in older patients (aged $>64$ years) and were compared with toxicity data from patients aged $<60$ and those aged 60-64 years treated in the same studies. Patients older than 64 years were described as 'elderly' patients in line with the publications $[12,13]$.

In the ADEBAR trial (NCT00047099), patients received 4 cycles of adjuvant therapy either with epirubicin/cyclophosphamide $(90 / 600 \mathrm{mg} /$ $\mathrm{m}^{2}$ ) every 3 weeks (q3w) followed by 4 cycles of docetaxel $\left(100 \mathrm{mg} / \mathrm{m}^{2}\right)$ $\mathrm{q} 3 \mathrm{w}$, or 6 cycles of 5 -fluorouracil/epirubicin $\left(500 / 60 \mathrm{mg} / \mathrm{m}^{2}\right)$ intraveneously (i.v.) on days 1 and 8 , and cyclophosphamide $\left(75 \mathrm{mg} / \mathrm{m}^{2}\right)$ orally (p.o.) on days $1-14 \mathrm{q} 4 \mathrm{w}[14,15]$. The enrolment into the study was limited to patients aged $\geq 18$ to $\leq 70$ years with a life expectancy of at least 32 months. The patients only received secondary prophylaxis with granulocyte colony-stimulating factors (G-CSF) if febrile, severe or prolonged neutropenia occurred.

In the ASG 1-3 trial (NCT00668616), patients received 4 cycles of adjuvant therapy either with epirubicin/cyclophosphamide $\left(90 / 600 \mathrm{mg}^{2}\right)$ $\mathrm{q} 3 \mathrm{w}$ followed by 4 cycles of paclitaxel $\left(175 \mathrm{mg}^{2}\right) \mathrm{q} 3 \mathrm{w}$, or 4 cycles of epirubicin $\left(120 \mathrm{mg} / \mathrm{m}^{2}\right) \mathrm{q} 2 \mathrm{w}$ and then 4 cycles of paclitaxel $\left(175 \mathrm{mg} / \mathrm{m}^{2}\right) \mathrm{q} 2 \mathrm{w}$. Enrolment into the study was limited to patients aged $\geq 18$ to $\leq 75$ years Patients in the dose-dense (dd) arm receiving doxorubicin/docetaxel (AT) were given a primary prophylaxis with G-CSF on days 5-10. Patients with primary anti-infective therapy were not included in the study.

In the GeparDuo trial (NCT00543829), patients received 4 cycles of neoadjuvant therapy with doxorubicin/cyclophosphamide $\left(60 / 600 \mathrm{mg} / \mathrm{m}^{2}\right)$ q3w followed by 4 cycles of docetaxel $\left(100 \mathrm{mg} / \mathrm{m}^{2}\right) \mathrm{q} 3 \mathrm{w}$ or 4 cycles of AT $\left(50 / 75 \mathrm{mg} / \mathrm{m}^{2}\right) \mathrm{q} 2 \mathrm{w}$ [16]. Enrolment into the study was limited to patients aged $\geq 18$ years and with a life expectancy of $\geq 10$ years. All patients in the dd arm who received AT q2w were given primary prophylaxis with G-CSF on days 5-10. Antibiotic treatment was started only as a secondary prophylaxis.

In the GeparTrio trial (NCT00544765), patients received 2 cycles of neoadjuvant chemotherapy with docetaxel/doxorubicin/cyclophosphamide (TAC, $75 / 50 / 500 \mathrm{mg} / \mathrm{m}^{2}$ ) followed by either 4 cycles of TAC, 6 cycles of TAC, or 4 cycles of vinorelbine $\left(25 \mathrm{mg} / \mathrm{m}^{2}\right.$ on days 1 and 8$)$ plus capecitabine $\left(1,000 \mathrm{mg} / \mathrm{m}^{2}\right.$ on days $\left.1-14\right) \mathrm{q} 3 \mathrm{w}[17,18]$. Enrolment into the study was limited to patients aged $\geq 18$ years, with no upper age limit. In this trial, the supportive treatment has been amended during the course of the trial, starting with only antibiotic prophylaxis. The febrile neutropenia $(\mathrm{FN})$ prophylaxis regimen was stepwise intensified to G-CSF, pegfilgrastim and pegfilgrastim plus ciprofloxacin [19].

Dose delays and dose reductions were performed according to special steps predefined in the protocol. In the following, when the term 'compliance' is used, it refers to the adherence to the planned chemotherapy as defined in the individual protocols, in terms of dose reduction, dose discontinuation and dose delays in total. In this paper, only the anthracycline-containing cycles were analyzed. Further details regarding the study designs have been described elsewhere [9].

The chemotherapy schedules were grouped as follows:

- TAC: Docetaxel/doxorubicin/cyclophosphamide i.v. q3w;

- Canadian $\mathrm{FE}_{120} \mathrm{C}$ : 5-fluorouracil/epirubicin i.v. days 1 and 8 followed by cyclophosphamide p.o. days $1-14 \mathrm{q} 4 \mathrm{w}$;

- A(E)C-[T/P]: doxorubicin(epirubicin)/cyclophosphamide (60(90)/ $\left.600 \mathrm{mg} / \mathrm{m}^{2}\right)$ i.v. $\mathrm{q} 3 \mathrm{w}$ followed by docetaxel $\left(100 \mathrm{mg} / \mathrm{m}^{2}\right)$ or paclitaxel $\left(175 \mathrm{mg} / \mathrm{m}^{2}\right) \mathrm{q} 3 \mathrm{w}$;

- ddAT: dd doxorubicin/docetaxel $\left(50 / 75 \mathrm{mg} / \mathrm{m}^{2}\right) \mathrm{q} 2 \mathrm{w}$;

- ddE-ddP: dd epirubicin followed by paclitaxel $\left(120 / 175 \mathrm{mg} / \mathrm{m}^{2}\right) \mathrm{q} 2 \mathrm{w}$.

The protocols were reviewed by all responsible local ethics committees and competent authorities. All patients gave written informed consent for participating in the individual trials.

\section{Data Collection and Statistical Analyses}

Data on dose delays and dose reductions, hospitalizations, treatment discontinuations, deaths, and hematological and non-hematological toxicities were collected. For hematological toxicity, not all records of all cycles included the same data on the respective events: FN data were recorded for patients on the TAC regimen; all other patients were considered to have $\mathrm{FN}$ of at least grade 3 in a given chemotherapy cycle if they had grade $3+4$ neutropenia, more than grade 1 fever, and no infection. All FN cases reported as serious adverse events with severity grade were also considered. In cycles where at least 1 of the 3 parameters (neutropenia, fever, infection) was missing, and FN was not reported in the serious adverse events description, the cycle was considered as having a missing value for FN. All statistical analyses were exploratory and no adjustments were made for multiple comparison. Calculations were performed using 
SPSS 14.0.1 for Windows (SPSS Inc. Chicago, IL, USA). Grading systems for toxicities in different studies were checked for consistency and were converted into National Cancer Institute Common Terminology Criteria version 3 (NCI-CTCAE 3.0) grades. Pearson's chi-squared test was performed to compare incidences of toxicity endpoints.

\section{Results}

This analysis is based on data from 4 German studies including a total of 4,775 patients receiving an anthracycline-containing chemotherapy regimen for primary BC. A total of 22,306 anthracycline-containing chemotherapy cycles were administered, $74.8 \%(\mathrm{n}=16,679)$ to patients aged $<60$ years, $15.2 \%(\mathrm{n}=3,389)$ to patients between 60 and 64 years and
$10 \%(\mathrm{n}=2,238)$ to patients aged $>64$ years. The main baseline characteristics are summarized in table 1.

\section{Dose Delays, Dose Reductions, and Early Discontinuations}

Dose delays were reported in $10.2 \%$ and treatment discontinuations due to toxicity in $10.3 \%$ of all patients who started treatment. The $\mathrm{FE}_{120} \mathrm{C}$ regimen was the most toxic with dose reduction of $21.5 \%$ in total $(15.7 \%$ in the $<60,26.9 \%$ in the $60-64$, and $39.9 \%$ in the $>64$ year age groups; $\mathrm{p}<0.001)$, dose delays of $26.8 \%$ in total $(24.7 \%$ in the $<60,32.4 \%$ in the $60-64$, and $28.6 \%$ in the $>64$ year age groups; $p=0.266)$ and early treatment discontinuation of $16.6 \%$ in total $(13.2 \%$ in the $<60,20.2 \%$ in the $60-64$, and $26.8 \%$ in the $>64$ year age groups; $\mathrm{p}=0.007)$.

Table 1. Baseline characteristics of the whole population

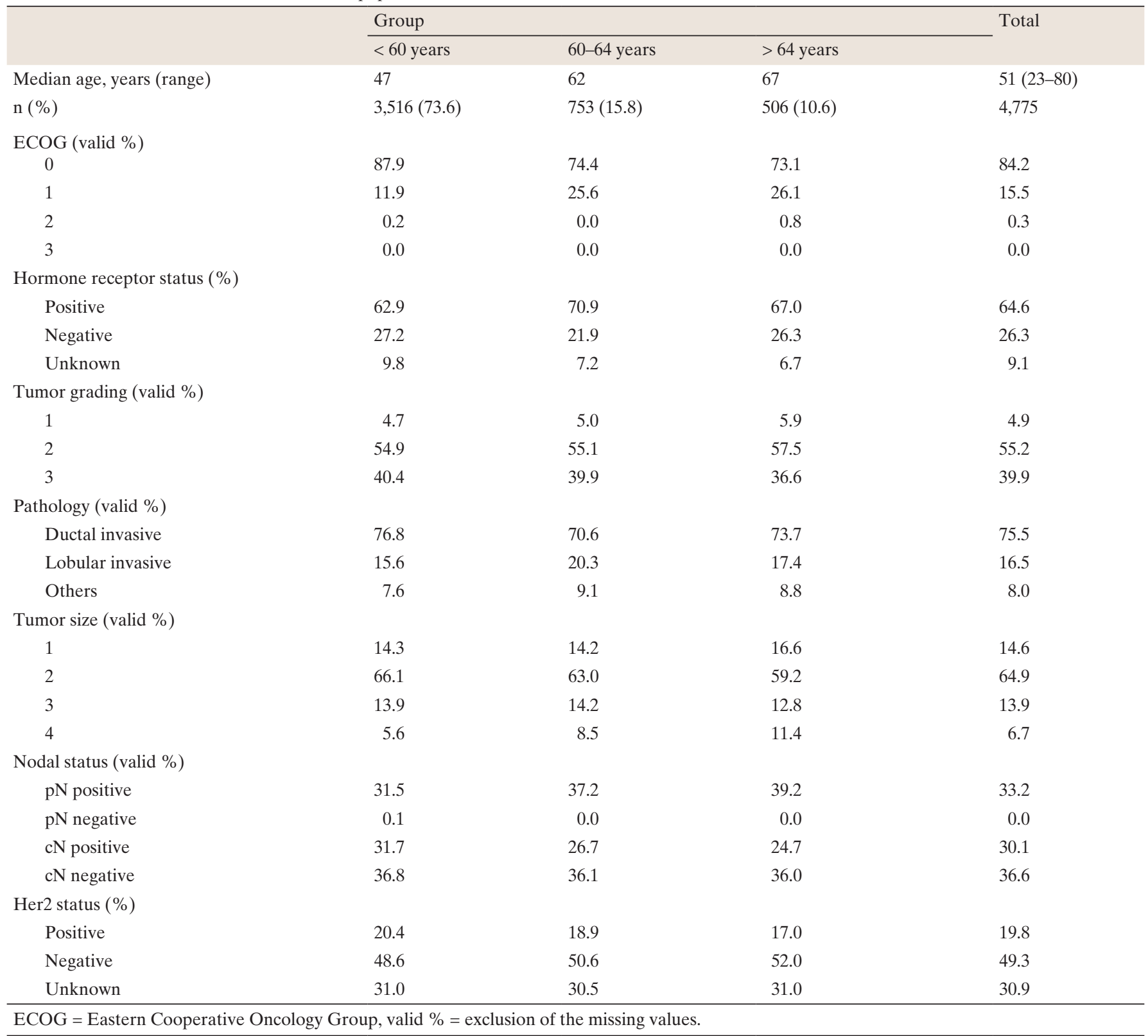


Comparing the dd regimens with each other, the overall dose delays were comparable with the $9.1 \%$ for the ddAT schedule and $9.6 \%$ for the ddE-ddP schedule. The reported incidences of dose delays during ddAT steadily increased with age $(5.8 \%$ in the $<60,17.3 \%$ in the $60-64$, and $20.0 \%$ in the $>64$ year age groups; $p$ overall $<0.001)$, whereas during the ddE-ddP regimen there was no significant differences between the age groups $(9.1 \%, 14.5 \%$, and $7.0 \%$ respectively).

\section{Hematological Toxicity}

The rate of neutropenia grade $3+4$ and $\mathrm{FN}$ for the applied regimens are given in table 2 . The incidence of these hematological toxicities varied by regimen and age. More-intense regimens such as $\mathrm{FE}_{120} \mathrm{C}$ were associated with more grade 3-4 hematological toxicity than less-intense regimens such as $\mathrm{A}(\mathrm{E}) \mathrm{C}-[\mathrm{T} / \mathrm{P}]$. Analyzing older versus younger patients, the per-patient incidence of grade 3-4 hematological adverse events generally increased with age, regardless of the chemotherapy regimen administered. The rate of neutropenia grade 3-4 increased significantly from the younger to the elderly group. Results comparable to the rate of neutropenia grade $3+4$ were found for the rate of leukopenia grade $3+4$, which also showed a significant increase with age. The rates of FN were not significantly different between the age groups.

The incidence of FN of all grades was lowest in the regimens without an additional taxane $\left(\mathrm{FE}_{120} \mathrm{C}\right.$ regimen with $2.9 \%$, ddE-ddP regimen with $0.9 \%$ and $\mathrm{A}(\mathrm{E}) \mathrm{C}-[\mathrm{T} / \mathrm{P}]$ with $1.0 \%$ for all patients) in comparison to the TAC (10\%) and the ddAT schedule $(4.7 \%)$. Further details for neutropenia and FN grade $3+4$ according to the patients' age are summarized in table 2 .

\section{Non-hematological Toxicity}

Not all non-hematological toxicities were recorded consistently for each chemotherapy regimen and all cycles in the individual trials. A summary of the reported events with regards to the different age groups are shown in table 3. The non-hematological toxicities included nausea, vomiting, diarrhea, stomatitis, sensory neuropathy and changes in kidney or liver function. Non-hematological toxicities varied less between the age groups.

Diarrhea grade 1-4 was less frequently reported when an anthracycline monotherapy was administered. The overall incidence of sensory neuropathy of any grade was higher in anthracycline- and taxane-containing schedules such as TAC $(47.3 \%)$ and ddAT $(46.0 \%)$ than in $\mathrm{FE}_{120} \mathrm{C}(21.5 \%)$, $\mathrm{A}(\mathrm{E}) \mathrm{C}-[\mathrm{T} / \mathrm{P}](18.7 \%)$, and ddE-[ddP] $(16.8 \%)$ where anthracyclines were given without concurrent taxanes.

\section{Discussion}

In this pooled retrospective analysis of individual patient data from 4 randomized clinical trials, we describe the compliance, and hematological, and non-hematological side effects of 5 different anthracycline-containing chemotherapy regimens for women with primary $\mathrm{BC}$, with the focus on the elderly population. The analysis separated the toxicities according to patients' ages into 3 groups: patients of $<60$, those between 60 and 64 and those $>64$ years. Elderly patients were defined by age $>64$ years.

Overall, the compliance decreased with age, independent of the applied chemotherapy regimens. The $\mathrm{FE}_{120} \mathrm{C}$ schedule

Table 2. Incidences of hematological toxicity

\begin{tabular}{|c|c|c|c|c|c|}
\hline & \multicolumn{3}{|c|}{ Age groups, years } & \multirow[b]{2}{*}{ Total } & \multirow[t]{2}{*}{ Overall $p$ value } \\
\hline & $<60$ & $60-64$ & $>64$ & & \\
\hline \multicolumn{6}{|l|}{ Neutropenia grade $3+4^{*}$} \\
\hline $\mathrm{n}$ & 1,243 & 362 & 278 & 1,883 & \\
\hline \multicolumn{6}{|l|}{ Treatment, \% } \\
\hline TAC & 37.5 & 56.7 & 55.2 & 43.0 & $<0.001$ \\
\hline Canadian $\mathrm{FE}_{120} \mathrm{C}$ & 67.0 & 62.6 & 76.5 & 67.7 & 0.127 \\
\hline $\mathrm{A}(\mathrm{E}) \mathrm{C}-[\mathrm{T} / \mathrm{P}]$ & 52.8 & 52.0 & 65.5 & 54.2 & 0.012 \\
\hline ddAT & 43.5 & 47.4 & 43.6 & 44.2 & 0.815 \\
\hline ddE-ddP & 29.7 & 36.7 & 33.3 & 31.1 & 0.599 \\
\hline \multicolumn{6}{|c|}{ Febrile neutropenia grade $3+4^{*}$} \\
\hline $\mathrm{n}$ & 172 & 43 & 30 & 245 & \\
\hline \multicolumn{6}{|l|}{ Treatment, \% } \\
\hline TAC & 9.3 & 11.3 & 14.3 & 10.0 & 0.088 \\
\hline Canadian $\mathrm{FE}_{120} \mathrm{C}$ & 2.5 & 4.7 & 2.4 & 2.9 & 0.498 \\
\hline $\mathrm{A}(\mathrm{E}) \mathrm{C}-[\mathrm{T} / \mathrm{P}]$ & 1.0 & 0.5 & 1.4 & 1.0 & 0.686 \\
\hline ddAT & 4.5 & 5.1 & 5.1 & 4.7 & 0.960 \\
\hline ddE-ddP & 0.0 & 6.4 & 0.0 & 0.9 & $<0.001$ \\
\hline
\end{tabular}

$\mathrm{F}=$ 5-fluouracil, $\mathrm{A}$ : adriamycin, $\mathrm{E}=$ epirubicin, $\mathrm{C}=$ cyclophosphamide, $\mathrm{T}=$ docetaxel, $\mathrm{P}=$ paclitaxel, $\mathrm{dd}=$ dose dense.

"According to the National Cancer Institute Common Toxicity Criteria. 
Table 3. Incidences of non-hematological side effects

\begin{tabular}{|c|c|c|c|c|c|}
\hline & \multicolumn{3}{|c|}{ Age groups, years } & \multirow[b]{2}{*}{ Total } & \multirow[t]{2}{*}{ Overall p value } \\
\hline & $<60$ & $60-64$ & $>64$ & & \\
\hline \multicolumn{6}{|l|}{ Fatigue grade $3+4^{*}$} \\
\hline \multicolumn{6}{|l|}{ Treatment, \% (n) } \\
\hline TAC & $11.6(175)$ & $12.7(34)$ & $17.1(29)$ & $12.2(238)$ & 0.113 \\
\hline Canadian $\mathrm{FE}_{120} \mathrm{C}$ & - & - & - & - & - \\
\hline $\mathrm{A}(\mathrm{E}) \mathrm{C}-[\mathrm{T} / \mathrm{P}]$ & $8.5(28)$ & $11.8(8)$ & $16.0(8)$ & $44(9.8)$ & 0.208 \\
\hline ddAT & $24.7(81)$ & $39.5(32)$ & $35.0(14)$ & $28.3(127)$ & 0.018 \\
\hline \multirow{2}{*}{\multicolumn{6}{|c|}{ Stomatitis grade $3+4^{*}$}} \\
\hline & & & & & \\
\hline \multicolumn{6}{|l|}{ Treatment, \% (n) } \\
\hline TAC & $3.6(54)$ & $3.7(10)$ & $5.9(10)$ & $3.8(74)$ & 0.328 \\
\hline Canadian $\mathrm{FE}_{120} \mathrm{C}$ & $6.8(24)$ & $9.3(10)$ & $14.5(12)$ & $8.4(46)$ & 0.073 \\
\hline $\mathrm{A}(\mathrm{E}) \mathrm{C}-[\mathrm{T} / \mathrm{P}]$ & $1.2(12)$ & $0.4(1)$ & $2.4(4)$ & $1.2(17)$ & 0.203 \\
\hline ddAT & $2.8(9)$ & $7.4(6)$ & $5.0(2)$ & $3.8(17)$ & 0.133 \\
\hline ddE-ddP & $2.1(6)$ & $13.2(7)$ & $11.9(5)$ & $4.8(18)$ & $<0.001$ \\
\hline \multicolumn{6}{|l|}{ Diarrhea grade $3+4^{*}$} \\
\hline \multicolumn{6}{|l|}{ Treatment, \% (n) } \\
\hline TAC & $3.5(53)$ & $3.4(9)$ & $8.2(14)$ & $3.9(76)$ & 0.010 \\
\hline Canadian $\mathrm{FE}_{120} \mathrm{C}$ & $1.4(5)$ & $3.7(4)$ & $2.4(2)$ & $2.0(11)$ & 0.321 \\
\hline $\mathrm{A}(\mathrm{E}) \mathrm{C}-[\mathrm{T} / \mathrm{P}]$ & $0.4(4)$ & $0.0(0)$ & $0.0(0)$ & $0.3(4)$ & 0.446 \\
\hline ddAT & $8.3(27)$ & $7.4(6)$ & $2.5(1)$ & $7.6(34)$ & 0.430 \\
\hline ddE-ddP & $0.7(2)$ & $0.0(0)$ & $0.0(0)$ & $0.5(2)$ & 0.711 \\
\hline \multicolumn{6}{|c|}{ Sensory neuropathy grade $3+4^{*}$} \\
\hline \multicolumn{6}{|c|}{ Treatment, \% (n) } \\
\hline TAC & $1.1(17)$ & $2.2(6)$ & $1.8(3)$ & $1.3(26)$ & 0.303 \\
\hline Canadian $\mathrm{FE}_{120} \mathrm{C}$ & $0.6(2)$ & $0.0(0)$ & $0.0(0)$ & $0.4(2)$ & 0.581 \\
\hline $\mathrm{A}(\mathrm{E}) \mathrm{C}-[\mathrm{T} / \mathrm{P}]$ & $0.1(1)$ & $0.0(0)$ & $0.0(0)$ & $0.1(1)$ & 0.817 \\
\hline ddAT & $0.9(3)$ & $2.5(2)$ & $0.0(0)$ & $1.1(5)$ & 0.384 \\
\hline ddE-ddP & $0.0(0)$ & $0.0(0)$ & $0.0(0)$ & $0.0(0)$ & - \\
\hline \multicolumn{6}{|c|}{ Increase of liver enzymes grade $3+4^{*}$} \\
\hline \multicolumn{6}{|c|}{ Treatment, \% (n) } \\
\hline TAC & $2.3(34)$ & $2.3(5)$ & $2.0(3)$ & $2.2(42)$ & 0.981 \\
\hline Canadian $\mathrm{FE}_{120} \mathrm{C}$ & $2.1(7)$ & $1.9(2)$ & $2.5(2)$ & $2.1(11)$ & 0.960 \\
\hline $\mathrm{A}(\mathrm{E}) \mathrm{C}-[\mathrm{T} / \mathrm{P}]$ & $2.1(20)$ & $2.3(5)$ & $0.0(0)$ & $1.9(25)$ & 0.183 \\
\hline ddAT & $1.8(6)$ & $5.0(4)$ & $7.5(3)$ & $2.9(13)$ & 0.064 \\
\hline ddE-ddP & $10.3(28)$ & $3.8(2)$ & $0.0(0)$ & $8.3(30)$ & 0.050 \\
\hline \multicolumn{6}{|c|}{ Increase of creatinine grade $3+4^{*}$} \\
\hline \multicolumn{6}{|c|}{ Treatment, \% (n) } \\
\hline TAC & $4.5(68)$ & $9.3(25)$ & $9.5(16)$ & $5.6(109)$ & $<0.001$ \\
\hline Canadian $\mathrm{FE}_{120} \mathrm{C}$ & - & - & - & - & - \\
\hline $\mathrm{A}(\mathrm{E}) \mathrm{C}-[\mathrm{T} / \mathrm{P}]$ & $0.5(3)$ & $2.4(3)$ & $1.2(1)$ & $0.9(7)$ & 0.124 \\
\hline ddAT & $1.2(4)$ & $1.3(1)$ & $2.5(1)$ & $1.4(6)$ & 0.804 \\
\hline ddE-ddP & $0.0(0)$ & $3.7(2)$ & $8.6(3)$ & $1.4(5)$ & $<0.001$ \\
\hline
\end{tabular}

$\mathrm{F}=$ 5-fluouracil, $\mathrm{A}$ : adriamycin, $\mathrm{E}=$ epirubicin, $\mathrm{C}=$ cyclophosphamide, $\mathrm{T}=$ docetaxel, $\mathrm{P}=$ paclitaxel, $\mathrm{dd}=\mathrm{dose}$ dense.

*According to the National Cancer Institute Common Terminology Criteria (Version 3 Terminology).

was most problematic with a particularly high incidence of dose delays, dose reductions, and therapy discontinuations. This was seen for the elderly in our analysis as well as in studies of other groups [20,21]. Nevertheless, some authors found in a retrospective analysis that age per se was not an indicator for decreasing compliance, which appeared to be related to co-morbidities and BC stage [22].

Hematological toxicities increased with age. The lowest incidence of hematological side effects was noticed for neutropenia and FN in the ddE-ddP schedule, despite the dd regimen. The highest incidence of neutropenia was reported for patients receiving $\mathrm{FE}_{120} \mathrm{C}$. The highest rate of $\mathrm{FN}$ was reported for TAC. The toxicity of ddAT or $\mathrm{FE}_{120} \mathrm{C}$ was in agreement with the findings of other study groups, who reported similarly high results of adverse hematological events, which also increased in the elderly $[21,23]$.
The high rate of hematological side effects can be countered with G-CSF. This was used in the dd regimens (ddAT, ddE-ddP) as a primary prophylaxis, and stepwise in patients receiving TAC to help them adhere to the appropriate and most effective dosing [24] that is part of many clinical trials [25-27]. No primary prophylaxis was implemented in the ADEBAR trial, but secondary prophylaxis with G-CSF was given to more than $60 \%$ [28] of those receiving $\mathrm{FE}_{120} \mathrm{C}$. The European Organisation for Research and Treatment of Cancer (EORTC) guidelines [29] recommend primary prophylaxis with G-CSF when the risk for FN of the regimen is $20 \%$, or when the FN risk of the regimen is between 10 and $20 \%$ in high-risk patients (e.g. $>65$ years). Age is the most notedd risk factor for $\mathrm{FN}$.

In our cohort, the frequency and severity of non-hematological side effects were as expected from the known side- 
effect profile of the agents used. Sensory neuropathy grade $3+4$ occurred more often in patients receiving a taxanecontaining therapy. The elderly do not necessarily suffer more from those side effects, as the comparison between the age groups did not show significant differences. Mucositis grade $3+4$ was less frequently reported in patients receiving $\mathrm{A}(\mathrm{E}) \mathrm{C}-[\mathrm{T} / \mathrm{P}]$ than in patients receiving any kind of $\mathrm{dd}$ or dose-intensified therapy. The elderly patients seemed to suffer more from mucositis grade $3+4$ than younger patients, but only the ddE-ddP regimen showed significant differences between the age groups, with a peak between 60 and 64 years.

There are no follow-up data available for this analysis. Therefore, the final results regarding long-term toxicities are missing. In addition, there are no data available on relapses or responses $[16,18,28,30]$. The analysis has its limitations as it has been done as a post-hoc analysis. Long-term toxicity is lacking and the toxicity data have not been linked to outcome data. However, the large sample size supports the findings. However, the number of patients who were 65 and older was low, despite the fact that only 1 study had an age limit of 65 years. This reflects current clinical trial practice for elderly patients. We have therefore started a trial with elderly patients comparing a taxane-containing combination therapy with 4 cycles of conventional epirubicin/cyclophospamide [31].

In conclusion, the dd and dose-intensified regimens induced more side effects. Our analysis showed that all analyzed age groups were able to cope with the therapeutic approaches. Elderly patients experienced more hematological side effects with the analyzed chemotherapies. However, not all of the elderly patients have received G-CSF as recommended by current guidelines. In general, sequential therapies were better tolerated than combination therapies, and dd therapies were also well tolerated in a sequential application design with the backup of G-CSF if necessary. $\mathrm{FE}_{120} \mathrm{C}$ is an effective regimen but, after evaluating the risk benefit, it does not seem to be an adequate alternative to sequential taxane-containing regimen especially in those $>64$ years.

\section{References}

1 Goldhirsch A, Glick JH, Gelber RD, Coates AS, Thurlimann B, Senn HJ: Meeting highlights: International expert consensus on the primary therapy of early breast cancer 2005. Ann Oncol 2005;16:1569-1583.

2 Albrand G, Terret C: Early breast cancer in the elderly: Assessment and management considerations. Drugs Aging 2008;25:35-45.

$\checkmark 3$ Biganzoli L, Wildiers H, Oakman C, Marotti L, Loibl S, Kunkler I, Reed M, Ciatto S, Voogd AC, Brain E, Cutuli B, Terret C, Gosney M, Aapro M, Audisio R: Management of elderly patients with breast cancer: Updated recommendations of the International Society of Geriatric Oncology (SIOG) and European Society of Breast Cancer Specialists (EUSOMA). Lancet Oncol 2012;13:e148-e160.

4 Treatment recommendations of the Arbeitsgemeinschaft Gynäkologische Onkologie (AGO), Mamma 2010; www.ago-online.de/delfuermediziner/leitlinien/mamma/.

5 Bouchardy C, Rapiti E, Fioretta G, Laissue P, Neyroud-Caspar I, Schafer P, Kurtz J, Sappino AP, Vlastos G: Undertreatment strongly decreases prognosis of breast cancer in elderly women. J Clin Oncol 2003;21:3580-3587.

6 Muss HB, Woolf S, Berry D, Cirrincione C, Weiss RB, Budman D, Wood WC, Hudis C, Winer E, Cohen H, Wheeler J, Norton L: Adjuvant chemotherapy in older and younger women with lymph node-positive breast cancer. JAMA 2005;293:1073-1081.

7 Muss HB, Berry DA, Cirrincione CT, Theodoulou M, Mauer AM, Kornblith AB, Partridge AH, Dressler LG, Cohen HJ, Becker HP, Kartcheske PA, Wheeler JD, Perez EA, Wolff AC, Gralow JR, Burstein HJ, Mahmood AA, Magrinat G, Parker BA, Hart RD, Grenier D, Norton L, Hudis CA, Winer EP: Adjuvant chemotherapy in older women with early-stage breast cancer. N Engl J Med 2009;360:2055-2065.

8 Early Breast Cancer Trialists' Collaborative Group (EBCTCG): Effects of chemotherapy and hor- monal therapy for early breast cancer on recurrence and 15-year survival: An overview of the randomised trials: Lancet 2005;365:1687-1717.

9 Loibl S, von Minckwitz G, Harbeck N, Janni W, Elling D, Kaufmann M, Eggemann H, Nekljudova V, Sommer H, Kiechle M, Kummel S: Clinical feasibility of (neo)adjuvant taxane-based chemotherapy in older patients: analysis of $>4,500$ patients from four German randomized breast cancer trials. Breast Cancer Res 2008;10:R77.

10 Pal SK, Hurria A: Impact of age, sex, and comorbidity on cancer therapy and disease progression. J Clin Oncol 2010;28:4086-4093.

11 Repetto L: Greater risks of chemotherapy toxicity in elderly patients with cancer. J Support Oncol 2003;1:18-24.

12 Pivot X, Schneeweiss A, Verma S, Thomssen C, Passos-Coelho JL, Benedetti G, Ciruelos E, Duenne AA, Miles DW: Efficacy and safety of bevacizumab in combination with docetaxel for the first-line treatment of elderly patients with locally recurrent or metastatic breast cancer: results from AVADO. Eur J Cancer 2011;47:2387-2395.

13 Lichtman SM, Hurria A, Cirrincione CT, Seidman AD, Winer E, Hudis C, Cohen HJ, Muss HB: Paclitaxel efficacy and toxicity in older women with metastatic breast cancer: Combined analysis of CALGB 9342 and 9840. Ann Oncol 2012;23:632_ 638.

14 Rack B, Janni W, Harbeck N, Zemzoun I, Strobl B, Klanner E, de Waal J, Schindlbeck C, Kiechle M, Sommer H: Phase III study evaluating the role of docetaxel in the adjuvant therapy of breast cancer patients with extensive lymph node involvement (4 nodes+) - ADEBAR study. Breast 2003;12 Suppl 1:S37

15 Janni W, Harbeck N, Sommer H: Sequential treatment with epirubicin/cyclophosphamide, followed by docetaxel is equieffective, but less toxic than $\mathrm{FEC}_{120}$ in the adjuvant treatment of breast cancer patients with extensive lymph node involvement: The German ADEBAR Phase III Study, Poster discussion, Poster no. 604, SABCS 2009.
16 von Minckwitz G, Raab G, Caputo A, Schutte M, Hilfrich J, Blohmer JU, Gerber B, Costa SD, Eidtmann H, Jackisch C, du BA, Kaufmann M: Doxorubicin with cyclophosphamide followed by docetaxel every 21 days compared with doxorubicin and docetaxel every 14 days as preoperative treatment in operable breast cancer: The GEPARDUO study of the German Breast Group. J Clin Oncol 2005;23:2676-2685.

17 von Minckwitz G, Kummel S, Vogel P, Hanusch C, Eidtmann H, Hilfrich J, Gerber B, Huober J, Costa SD, Jackisch C, Loibl S, Mehta K, Kaufmann M: Neoadjuvant vinorelbine-capecitabine versus docetaxel-doxorubicin-cyclophosphamide in early nonresponsive breast cancer: Phase III randomized GeparTrio trial. J Natl Cancer Inst 2008;100:542-551.

18 von Minckwitz G, Kummel S, Vogel P, Hanusch C Eidtmann H, Hilfrich J, Gerber B, Huober J, Costa SD, Jackisch C, Loibl S, Mehta K, Kaufmann M: Intensified neoadjuvant chemotherapy in early-responding breast cancer: Phase III randomized GeparTrio study. J Natl Cancer Inst 2008;100:552-562.

19 von Minckwitz G, Kummel S, du BA, Eiermann W, Eidtmann H, Gerber B, Hilfrich J, Huober J, Costa SD, Jackisch C, Grasshoff ST, Vescia S, Skacel T, Loibl S, Mehta KM, Kaufmann M: Pegfilgrastim +/- ciprofloxacin for primary prophylaxis with TAC (docetaxel/doxorubicin/cyclophosphamide) chemotherapy for breast cancer. Results from the GEPARTRIO study. Ann Oncol 2008;19:292-298.

20 Pentheroudakis G, Fountzilas G, Kalofonos HP, Golfinopoulos V, Aravantinos G, Bafaloukos D, Papakostas P, Pectasides D, Christodoulou C, Syrigos K, Economopoulos T, Pavlidis N: Palliative chemotherapy in elderly patients with common metastatic malignancies: A Hellenic Cooperative Oncology Group registry analysis of management, outcome and clinical benefit predictors. Crit Rev Oncol Hematol 2008;66:237-247. 
-21 Burnell M, Levine MN, Chapman JA, Bramwell V, Gelmon K, Walley B, Vandenberg T, Chalchal H, Albain KS, Perez EA, Pritchard K, O'Brien P, Shepherd LE: Cyclophosphamide, epirubicin, and fluorouracil versus dose-dense epirubicin and cyclophosphamide followed by paclitaxel versus doxorubicin and cyclophosphamide followed by paclitaxel in node-positive or high-risk nodenegative breast cancer. J Clin Oncol 2010;28:77-82 .

22 Du XL, Osborne C, Goodwin JS: Population-based assessment of hospitalizations for toxicity from chemotherapy in older women with breast cancer. J Clin Oncol 2002;20:4636-4642.

23 Kummel S, Krocker J, Kohls A, Breitbach GP, Morack G, Budner M, Blohmer JU, Lichtenegger W, Elling D: Dose-dense adjuvant chemotherapy for node-positive breast cancer in women 60 years and older: Feasibility and tolerability in a subset of patients in a randomized trial. Crit Rev Oncol Hematol 2006;58:166-175.

24 von Minckwitz G, Blohmer JU, Raab G, Lohr A, Gerber B, Heinrich G, Eidtmann H, Kaufmann M, Hilfrich J, Jackisch C, Zuna I, Costa SD: In vivo chemosensitivity-adapted preoperative chemotherapy in patients with early-stage breast cancer: The GEPARTRIO pilot study. Ann Oncol 2005;16:56-63.
25 Levine MN, Pritchard KI, Bramwell VH, Shepherd LE, Tu D, Paul N: Randomized trial comparing cyclophosphamide, epirubicin, and fluorouracil with cyclophosphamide, methotrexate, and fluorouracil in premenopausal women with node-positive breast cancer: Update of National Cancer Institute of Canada Clinical Trials Group Trial MA5. J Clin Oncol 2005;23:5166-5170.

26 Martin M, Segui MA, Anton A, Ruiz A, Ramos M, Adrover E, Rodriguez-Lescure A, Grosse R, Calvo L, Barnadas A, Isla D, Martinez del PP, Ruiz BM, Zaluski J, Arcusa A, Mel JR, Munarriz B, Llorca C, Jara C, Alba E, Florian J, Li J, Lopez Garcia-Asenjo JA, Saez A, Rios MJ, Almenar S, Peiro G, Lluch A: Adjuvant docetaxel for highrisk, node-negative breast cancer. N Engl J Med 2010;363:2200-2210.

27 Martin M, Pienkowski T, Mackey J, Pawlicki M, Guastalla JP, Weaver C, Tomiak E, Al-Tweigeri T, Chap L, Juhos E, Guevin R, Howell A, Fornander T, Hainsworth J, Coleman R, Modiano M, Pinter T, Tang SC, Colwell B, Prady C, Rodriguez-Lescure A, Hugh J, Loret C, Rupin M, Blitz S, Jacobs P, Murawsky M, Riva A, Vogel C: Adjuvant docetaxel for node-positive breast cancer. N Engl J Med 2005;352:2302-2313.

28 Janni W, Harbeck N, Sommer H: Final toxicity analysis of the ADEBAR phase III study evaluat- ing the role of docetaxel in the adjuvant therapy of breast cancer patients with extensive lymph node involvement, Poster no. 3069; 2007.

29 Aapro MS, Bohlius J, Cameron DA, Dal Lago L, Donnelly JP, Kearney N, Lyman GH, Weber DC, Zielinski C: 2010 update of EORTC guidelines for the use of granulocyte -colony stimulating factor to reducethe incidence of chemotherapy-induced febrile neutropenia in adult patients with lymphoproliferative disorders and solid tumours. Eur J Cancer. 2011;47:8-32.

30 Huober J, von Minckwitz G, Denkert C, Tesch H, Weiss E, Zahm DM, Belau A, Khandan F, Hauschild M, Thomssen C, Hogel B, DarbEsfahani S, Mehta K, Loibl S: Effect of neoadjuvant anthracycline-taxane-based chemotherapy in different biological breast cancer phenotypes: Overall results from the GeparTrio study. Breast Cancer Res Treat 2010;124:133-140.

31 von Minckwitz G: ICE II: An investigational randomized phase II study on epirubicin (E) plus cyclophospamide(C) (or CMF) vs. nab-paclitaxel plus capecitabine (PX) as adjuvant chemotherapy for elderly non frail patients with an increased risk for relapse of a primary carcinoma of the breast. Abstracts of ASCO 2010. J Clin Oncol 2010;28(15S):8s (suppl; abstr TPS 104). 